\title{
Biomass pyrolysis liquid to citric acid via 2-step bioconversion
}

\author{
Zhiguang Yang ${ }^{1,2^{*}}$, Zhihui Bai ${ }^{2}$, Hongyan Sun ${ }^{1}$, Zhisheng Yu' ${ }^{2}$ Xingxing $\mathrm{Li}^{1}$, Yifei Guo ${ }^{1}$ and Hongxun Zhang ${ }^{2}$
}

\begin{abstract}
Background: The use of fossil carbon sources for fuels and petrochemicals has serious impacts on our environment and is unable to meet the demand in the future. A promising and sustainable alternative is to substitute fossil carbon sources with microbial cell factories converting lignocellulosic biomass into desirable value added products. However, such bioprocesses require tolerance to inhibitory compounds generated during pretreatment of biomass. In this study, the process of sequential two-step bio-conversion of biomass pyrolysis liquid containing levoglucosan (LG) to citric acid without chemical detoxification has been explored, which can greatly improve the utilization efficiency of lignocellulosic biomass.

Results: The sequential two-step bio-conversion of corn stover pyrolysis liquid to citric acid has been established. The first step conversion by Phanerochaete chrysosporium (P. chrysosporium) is desirable to decrease the content of other compounds except levoglucosan as a pretreatment for the second conversion. The remaining levoglucosan in solution was further converted into citric acid by Aspergillus niger (A. niger) CBX-209. Thus the conversion of cellulose to citric acid is completed by both pyrolysis and bio-conversion technology. Under experimental conditions, levoglucosan yield is $12 \%$ based on the feedstock and the citric acid yield can reach $82.1 \%$ based on the levoglucosan content in the pyrolysis liquid (namely $82.1 \mathrm{~g}$ of citric acid per $100 \mathrm{~g}$ of levoglucosan).

Conclusion: The study shows that P. chrysosporium and A. niger have the potential to be used as production platforms for value-added products from pyrolyzed lignocellulosic biomass. Selected $P$. chrysosporium is able to decrease the content of other compounds except levoglucosan and levoglucosan can be further converted into citric acid in the residual liquids by $A$. niger. Thus the conversion of cellulose to citric acid is completed by both pyrolysis and bio-conversion technology.
\end{abstract}

Keywords: Lignocellulosic biomass, Pyrolysis, Levoglucosan, Bio-conversion, Citric acid

\section{Background}

Concern with environmental issues such as global climate change has stimulated research into the development of more environmentally friendly technologies and energy sources [1-4]. Wood and agricultural residues like corn stover are abundant and easily accessible at relatively low costs. This sustainable biomass has considerable advantages over petroleum-based sources and can be a reliable future source of added value chemicals and energy. Fast pyrolysis of lignocellulosic biomass for liquids

\footnotetext{
* Correspondence: yangzg1@126.com

'Department of Environmental and Municipal Engineering, Henan University of Urban Construction, Pingdingshan 467036, China

${ }^{2}$ Laboratory of Environmental Biotechnology, Research Center for

Eco-Environmental Sciences, Chinese Academy of Sciences, Beijing 100085,
} China

\section{Biomed Central}

production is of particular concern, as it is one of the interesting ways to produce renewable fuel and fine chemical precursors [5-8]. Their thermochemical conversion into gases and liquids used in gas turbines or diesel engines is one way to utilize these renewable resources. Cellulosic biomass can also be efficiently and rapidly converted into a high yield of pyrolysate with levoglucosan in high concentration under appropriate pyrolysis conditions $[9,10]$. The levoglucosan has attracted many investigators because its production and potential use as a fermentative carbon and energy source in the fermentation industry would lead to possible commercial utilization of large quantities of cellulosic materials [11,12]. However, during the pyrolysis of cellulosic materials, various toxic compounds, including aromatic species, aldehydes, furan and furfuryl derivatives, are formed, which inhibit the growth 
and fermentation of microorganisms [12-14]. Thus an additional and complicated detoxification step using many chemical reagents is needed to remove the inhibitors and improve microorganism growth prior to fermentation. It is disadvantageous because the process has large reagent consumption and waste production.

Phanerochaete chrysosporium is a filamentous basidiomycete white rot fungus, which is the subject of many investigations due to its ability to mineralize lignin and other related molecules $[15,16]$. The mineralization process is due to its peroxidases including lignin peroxidases (LiP), manganese-dependent peroxidases $(\mathrm{MnP})$ and laccases secreted during metabolism [17]. These peroxidases are powerful oxidants that can oxidize not only phenols and aromatic amines, but also a variety of other aromatic ethers and polycyclic aromatics with appropriate ionization potentials [18].

Only those microorganisms with a specific levoglucosan kinase can directly convert LG to valuable products [19]. Our previous studies show that A. niger CBX-209 can grow well on purified levoglucosan under optimum temperature, $\mathrm{pH}$, the concentration of levoglucosan and wheat bran in the medium [20,21]. In this study, the efficient utilization for pyrolysate is developed. The bioconversion process can be carried out in two steps. Other compounds except LG are utilized and converted by $P$. chrysosporium in the first step, and then remaining LG can be directly converted to citric acid by A. niger $C B X-$ 209 in the second step. Two-step direct bioconversion of LG is advantageous because it avoids chemical pretreatment. The pre-fermentation step will not require costly reagents, but it has another cost. For example, the construction of a holding tank for this step will increase the process cost.

\section{Results and discussion}

\section{The components of corn stover}

The properties of corn stover were described in Table 1 after drying at $100 \pm 5^{\circ} \mathrm{C}$. Corn stover predominantly contains cellulose (41.46\%), hemicellulose (32.63\%) and lignin (16.22\%). As comparison the values of references were also listed in Table 1 . The difference between them was mainly because of different sources.

Table 1 Analysis data of corn stover

\begin{tabular}{llll}
\hline Components analysis (wt.\%) & \multicolumn{2}{l}{ Elemental analysis (wt.\%) } \\
\hline Cellulose & $41.46(37.5)^{\mathrm{b}}$ & $\mathrm{C}$ & $48.80(45.53)^{\mathrm{c}}$ \\
Hemicellulose & $32.63(20.8)^{\mathrm{b}}$ & $\mathrm{H}$ & $6.15(5.03)^{\mathrm{c}}$ \\
Lignin & $16.22(17.6)^{\mathrm{b}}$ & $\mathrm{N}$ & $0.78(0.78)^{\mathrm{c}}$ \\
Neutral detergent solutes & $8.88(--)^{\mathrm{b}}$ & $\mathrm{O}^{\mathrm{a}}$ & $44.27(41.11)^{\mathrm{c}}$ \\
& & $\mathrm{S}$ & $--(0.13)^{\mathrm{c}}$ \\
Ash & $0.81(--)^{\mathrm{b}}$ & & \\
\hline
\end{tabular}

${ }^{\mathrm{a}}$ Calculated by difference, ${ }^{\mathrm{b}}$ reference [22], ${ }^{\mathrm{C}}$ reference [23], -- no data.

\section{The pyrolysis liquid}

Under this pyrolysis condition, the pyrolysis liquid yield is $68.8 \%$, and its $\mathrm{pH}$ value is 2.8 . The highest amount of separate organic compound groups analyzed in the water phase consisted of low molecular pyrolysis products, such as acetic acid, oxalaldehyde, levoglucosan, acetol, furan, furfuryl and other compounds (Figure 1). The main product was levoglucosan and its proportion of the total products was about $17.5 \%$.

\section{First step bio-conversion}

The previous results showed that both Pc and An can grow using pyrolysis oil as carbon source [24]. The pyrolysis liquid can be used as carbon source for $P$. chrysosporium EBL0511 to grow at higher concentration, possibly because of higher concentration of hydrogen ion. The system of ligninolytic enzyme from $P$. chrysosporium is composed of lignin peroxidase, manganese peroxidase and glyoxal oxidase, which has a special degrading mechanism [25]. Similar to the oxidation of malonate by Manganese peroxidase (MnP) [26], for example, its biochemical reactions involved in the oxidation of glycolaldehyde by $\mathrm{MnP}$ are proposed as following 0ons (1, 2, 3, 4, 5, 6, 7, 8 and 9):

$$
\begin{aligned}
\mathrm{HOCH}_{2}-\mathrm{CHO} & +\mathrm{Mn}(\mathrm{III})+\frac{1}{2} \mathrm{O}_{2} \rightarrow \mathrm{HOCH}_{2}+\mathrm{CO}_{2} \\
& +\mathrm{H}^{+}+\mathrm{Mn}(\mathrm{II}) \\
\mathrm{HOCH}_{2}+\mathrm{O}_{2} \rightarrow \mathrm{HOCH}_{2} \mathrm{OO} & \\
\mathrm{HOCH}_{2} \mathrm{OO}+ & \mathrm{Mn}(\mathrm{II})+\mathrm{H}^{+} \rightarrow \mathrm{HOCH}_{2} \mathrm{OOH} \\
+ & \mathrm{Mn}(\mathrm{III})
\end{aligned}
$$

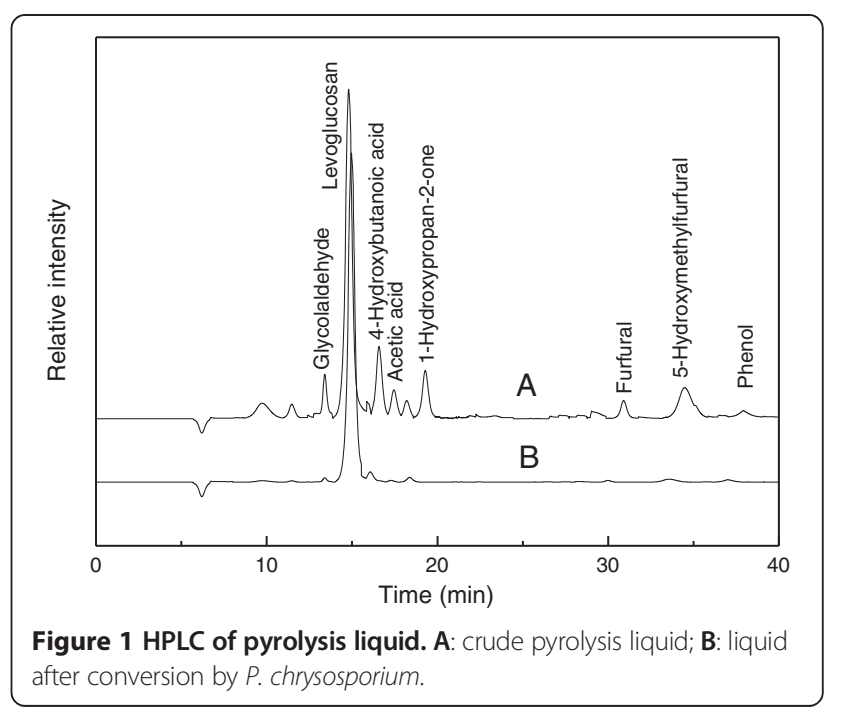




$$
\begin{aligned}
& \mathrm{HOCH}_{2} \mathrm{OOH}+2 \mathrm{Mn}(\mathrm{II}) \stackrel{\mathrm{MnP}}{\rightarrow} \mathrm{HOCHO}+\mathrm{H}_{2} \mathrm{O} \\
& +2 \mathrm{Mn}(\mathrm{III}) \\
& \mathrm{HOCH}_{2} \mathrm{OO}+\mathrm{O}_{2} \rightarrow \mathrm{H}_{2} \mathrm{O}+\mathrm{CO}_{2}+\mathrm{O}_{2}^{-\ddot{*}}+\mathrm{H}^{+} \\
& \mathrm{HOCHO}+\mathrm{Mn}(\mathrm{II})+\frac{1}{2} \mathrm{O}_{2} \rightarrow \mathrm{H}_{2} \mathrm{O}+\mathrm{CO}_{2}^{--}+\mathrm{Mn}(\mathrm{III}) \\
& \mathrm{CO}_{2}^{--}+\mathrm{O}_{2} \rightarrow \mathrm{CO}_{2}+\mathrm{O}_{2}^{--} \\
& \mathrm{O}_{2}^{--}+2 \mathrm{H}^{+}+\mathrm{Mn}(\mathrm{II}) \rightarrow \mathrm{H}_{2} \mathrm{O}_{2}+\mathrm{Mn}(\mathrm{III}) \\
& \mathrm{H}_{2} \mathrm{O}_{2}+\mathrm{Mn}(\mathrm{II}) \stackrel{\mathrm{MnP}}{\rightarrow} \mathrm{H}_{2} \mathrm{O}+2 \mathrm{Mn}(\mathrm{III})
\end{aligned}
$$

Figure 1 shows the changes in components after 7-days liquid cultures. P. chrysosporium EBL0511 is effective for degradation of pyrolysis liquid. Other components except levoglucosan were almost completely degraded by it.

\section{Second step bio-conversion}

The previous results showed that some components of pyrolysis liquid inhibited the growth of $A$. niger, but levoglucosan can be used as carbon source for it. Reports $[27,28]$ have found some microorganisms can assimilate levoglucosan, one of the components of pyrolysis liquid by phosphorylation to glucose 6-phosphate in the presence of magnesium ion and ATP (10):
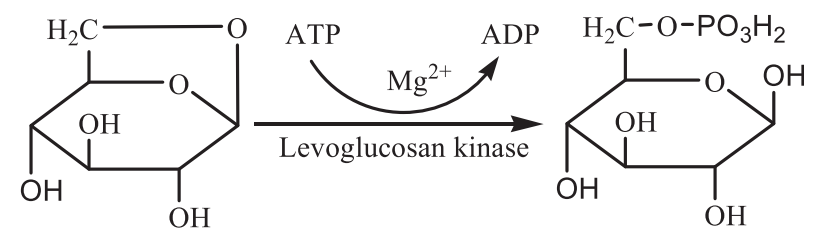

(10)

The liquid after the first conversion was further fermented to citric acid by $A$. niger $C B X-209$. The time course of citric acid fermentation is shown in Figure 2. Very little citric acid is produced for crude pyrolysis liquid. It means that some components of pyrolysis liquid have toxic effects on the growth of A. niger CBX-209. However the citric acid yield reaches $82.1 \%$ when using pyrolysis liquid after the first conversion. Accumulation of citric acid by $A$. niger $C B X-209$ could be divided into three steps. During the first step from inoculation to $24 \mathrm{~h}$, very little citric acid was produced due to lower biomass. In the second phase that lasted from 24 to $72 \mathrm{~h}$, the citric acid yield increased from about $1.8 \%$ to $82.1 \%$ rapidly with increasing biomass. The highest citric acid yield is slightly lower than the yield (87.5\%) when using purified levoglucosan as the sole carbon source [21]. In the third step, after $72 \mathrm{~h}$, the yield was maintained at almost the same level. The high yield of citric

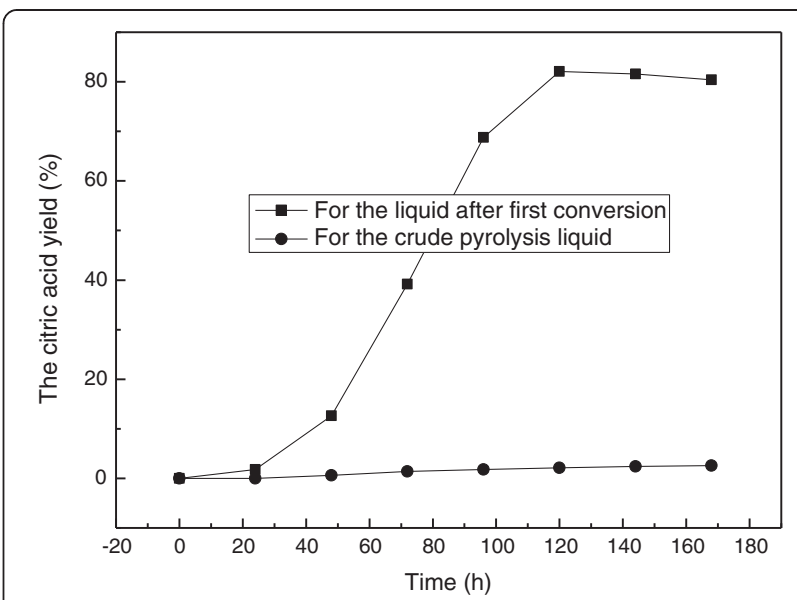

Figure 2 Course of the fermentation for the liquid after first conversion and the crude pyrolysis liquid.

acid by $A$. niger $C B X-209$ should be attributed to low molecular weight of LG and highly active microbe.

\section{Conclusions}

To obtain citric acid from corn stover pyrolysis liquid, serial 2-step conversion is established. In the first step conversion by $P$. chrysosporium, other compounds except levoglucosan are metabolized. Thus it can be used as a pretreatment for the second conversion. In the second step the liquids containing levoglucosan are further converted into citric acid by $A$. niger $C B X-209$. The result of serial conversion of corn stover pyrolysis liquid shows that the citric acid yield can reach $82.1 \%$ based on the levoglucosan in the pyrolysis liquid.

\section{Materials and methods Materials}

The corn stover used in all the experiments was obtained from Juxian field (Shandong province, China). It was oven dried at $100 \pm 5^{\circ} \mathrm{C}$ for $12 \mathrm{~h}$. The original length was between 2 and $50 \mathrm{~mm}$. It was partly ball-milled and screened to achieve a size of less than 20 mesh and larger than 48 mesh prior to the pyrolysis. The sample was analyzed by the elemental analyzer to determine the major elements such as carbon $(\mathrm{C})$, hydrogen $(\mathrm{H})$ and nitrogen $(\mathrm{N})$. The properties were described after drying at $100 \pm 5^{\circ} \mathrm{C}$. The determination of components was performed by the following procedure: a dried sample (1 g) - neutral detergent residue - acid detergent residue -72 wt.\% sulfuric acid detergent residue - ashing, where neutral detergent is $100 \mathrm{ml}$ water solution containing 1.86 g EDTA, $0.68 \mathrm{~g} \mathrm{Na}_{2} \mathrm{~B}_{4} \mathrm{O}_{7} \cdot 10 \mathrm{H}_{2} \mathrm{O}, 3$ g sodium dodecyl sulfate, $1 \mathrm{ml}$ glycol ether and $0.456 \mathrm{~g}$ $\mathrm{Na}_{2} \mathrm{HPO}_{4}$, acid detergent is $100 \mathrm{ml} 2 \mathrm{~mol} / \mathrm{L} \mathrm{HCl}$ solution containing $2 \mathrm{~g}$ Cetyl trimethyl ammonium bromide. Lignocellulose contents of all samples were determined 
by boiling in $100 \mathrm{ml}$ detergent solution for $1 \mathrm{hr}$ under reflux. Then these residues were filtered, washed with hot water and acetone, dried at $100^{\circ} \mathrm{C}$ for $8 \mathrm{hr}$ and weighed.

\section{Pyrolysis apparatus and procedures}

The self-designed pyrolyzer has been introduced and used in our previous works $[29,30]$. For the present work, briefly, the reaction system is evacuated by a rotary pump with an ultimate pressure of $6 \times 10^{-2} \mathrm{~Pa}$ and a pumping speed of $15 \mathrm{~L} / \mathrm{s}$. Reactor is loaded with a batch of feedstock (50 g), sealed and evacuated, then inserted into the furnace. Samples are pyrolyzed at a pre-set oven temperature $390^{\circ} \mathrm{C}$. Condensable product is collected in an ice-water condenser situated between the pyrolysis oven and the filter. At desired reaction time (here is $40 \mathrm{~min}$ ), reactor is pulled out of the furnace and watercooled and then after release of vacuum the residual is reweighed. The feedstock for pyrolysis is corn stover.

The pyrolysis liquid and its bio-conversion products are quantitatively diluted with distilled water and analyzed by a HPLC system (GRE-3A Shimadzu) equipped with a Waters Model 401 refractive index detector and a Transgenomic ICSep ICEORH- 801 column $(300 \mathrm{~mm} \times$ $6.5 \mathrm{~mm}$ ), the injection volume is $10 \mu \mathrm{l}$ and the column temperature is maintained at $48^{\circ} \mathrm{C}$. The eluent is $0.005 \mathrm{~mol} / \mathrm{L}$ sulfuric acid with flow rate of $0.6 \mathrm{ml} / \mathrm{min}$. Products are assayed by comparing the peak area for the sirup with that of the standard samples from Sigma. HPLC peaks are labeled based on the identical retention time with the standard samples. Each experiment is repeated three times and the mean of them is used for the analysis.

\section{Microorganisms and medium}

Microorganisms: P. chrysosporium EBL0511 (Pc) and A. niger $C B X-209$ (An) are used. Both of them are from our lab. Initially, P. chrysosporium EBL0511 was obtained from China General Microbiological Culture Collection Center. The mutant, A. niger CBX-209, was derived by $\gamma$-ray irradiation of spores of parent strain $C B X-2$, which has high citric acid productivity using starch as carbon and energy source at an industrial scale [20,21]. The solid medium was prepared by Potato medium (PM). PM contained 20\% Potato extract, $0.2 \%$ Glucose and $1.5 \%$ Agar. Blank medium (BM) used only agar and pyrolysis oil. The potato extract (Wako) was purchased from Express Technology Co., Ltd.

P. chrysosporium was used in the first step. The mutant, $A$. niger $C B X-209$ with high citric acid productivity was used in the second step. The seed culture had a composition of $20 \mathrm{~g} / \mathrm{L}$ glucose, $10 \mathrm{~g} / \mathrm{L}$ yeast extract, $1 \mathrm{~g} / \mathrm{L}$ $\mathrm{K}_{2} \mathrm{HPO}_{4}, 1 \mathrm{~g} / \mathrm{L} \mathrm{MgSO}_{4} \cdot 7 \mathrm{H}_{2} \mathrm{O}$ and $20 \mathrm{~g} / \mathrm{L}$ peptone. The supernatant was collected by centrifugation from the liquid after first conversion, added $3 \%$ wheat bran, and go into the autoclave then inoculate with $A$. niger $C B X-209$. The fermentation media incubated at $35^{\circ} \mathrm{C}$ on a rotary shaker at $400 \mathrm{rpm}$ for 5 days, and used for the analyses. Three replicates were performed for each fermentation experiment and each yield was the mean of three replicates.

The pyrolysis liquid needs to be diluted with equal amount of distilled water and then neutralized using $\mathrm{Na}_{2} \mathrm{CO}_{3}$ to $\mathrm{pH} 6.0$ before it was added into mediums.

\section{Abbreviations}

LG: Levoglucosan; MnP: Manganese peroxidase; PC: Phanerochaete chrysosporium; An: Aspergillus niger; PM: Potato medium; BM: Blank medium.

\section{Competing interests}

The authors declare that they have no competing interest.

\section{Authors' contributions}

$Z Y$ contributed to work including generating data and writing the manuscript. $Z B$ and $Y G$ helped in designing experiments. $Z B, Z Y$ and $H Z$ donated $P$. chrysosporium and $A$. niger. $H S$ helped in collecting data and $Y G$ helped in processing it. $Z Y, Z B, H S, Z Y, H Z, Y G$ and $L X$ have proof read the manuscript. All authors read and approved the final manuscript.

\section{Acknowledgments}

This work was financially supported by National Natural Science Foundation of China (No. 21177153), the Key Programs of the Chinese Academy of Sciences (No. KZZD-EW-09-3), National Science and Technology Major Project (No. 2014ZX07204-005) and the Key Technologies R\&D Program of China (No. 2012BAC25B01).

Received: 13 August 2014 Accepted: 12 December 2014

Published online: 31 December 2014

\section{References}

1. Zheng Y, Zhao J, Xu F, Li Y: Pretreatment of lignocellulosic biomass for enhanced biogas production. Prog Energ Combust 2014, 42:35-53.

2. Boguta A, Bringel F, Martinussen J, Jensen P: Screening of lactic acid bacteria for their potential as microbial cell factories for bioconversion of lignocellulosic feedstocks. Microb Cell Fact 2014, 13:97-113.

3. Behera S, Arora R, Nandhagopal N, Kumar S: Importance of chemical pretreatment for bioconversion of lignocellulosic biomass. Renew Sustain Ener Rev 2014, 36:91-106.

4. Okoli CO, Adams TA II: Techno-economic Analysis of a Thermochemical Lignocellulosic Biomass-to-Butanol Process. Comput Aided Chem Eng 2014, 33:1681-1686

5. Singh R, Shukla A, Tiwari S, Srivastava M: A review on delignification of lignocellulosic biomass for enhancement of ethanol production potential. Renew Sust Energ Rev 2014, 32:713-728.

6. Cai J, Wu W, Liu R: An overview of distributed activation energy model and its application in the pyrolysis of lignocellulosic biomass. Renew Sust Energ Rev 2014, 36:236-246.

7. López-González D, Fernandez-Lopez M, Valverde JL, Sanchez-Silva L. Gasification of lignocellulosic biomass char obtained from pyrolysis: Kinetic and evolved gas analyses. Energ 2014, 71:456-467.

8. Hu S, Li Y: Two-step sequential liquefaction of lignocellulosic biomass by crude glycerol for the production of polyols and polyurethane foams. Bioresource Technol 2014, 161:410-415.

9. Bai $X$, Johnston P, Brown RC: An experimental study of the competing processes of evaporation and polymerization of levoglucosan in cellulose pyrolysis. J Anal Appl Pyrol 2013, 99:130-136.

10. Bai $X$, Brown RC: Modeling the physiochemistry of levoglucosan during cellulose pyrolysis. J Anal Appl Pyrol 2014, 105:363-368.

11. Chi Z, Rover M, Jun E, Deaton M, Johnston P, Brown RC, Wen Z, Jarboe LR: Overliming detoxification of pyrolytic sugar syrup for direct fermentation of levoglucosan to ethanol. Bioresource Technol 2013, 150:220-227.

12. Shoji T, Kawamoto H, Saka S: Boiling point of levoglucosan and devolatilization temperatures in cellulose pyrolysis measured at different heating area temperatures. J Anal Appl Pyrol 2014, 109:185-195. 
13. Wimalasena TT, Greetham D, Marvin ME, Liti G, Chandelia Y, Hart A, Louis EJ, Phister TG, Tucker GA, Smart KA: Phenotypic characterisation of Saccharomyces spp. yeast for tolerance to stresses encountered during fermentation of lignocellulosic residues to produce bioethanol. Microb Cell Fact 2014, 13:47-60.

14. Yu Z, Zhang H: Ethanol fermentation of acid-hydrolyzed cellulosic pyrolysate with Saccharomyces cerevisiae. Bioresource Technol 2004, 93:199-204.

15. Michel FC, Dass SB, Grulke EA, Reddy CA: Role of manganese peroxidases and lignin peroxidases of Phanerochaete chrysosporium in the decolorization of kraft bleach plant effluent. Appl Environ Microbiol 1991, 57(8):2368-2375.

16. Reddy CA: The potential for white-rot fungi in the treatment of pollutants. Curr Opin Biotechnol 1995, 6(3):320-328.

17. Kuwahara M, Glenn JK, Morgan MA, Gold MH: Separation and characterization of two extracelluar $\mathrm{H}_{2} \mathrm{O}_{2}$-dependent oxidases from ligninolytic cultures of Phanerochaete chrysosporium. FEBS Lett 1984, 169(2):247-250.

18. Sanchez C: Lignocellulosic residues: biodegradation and bioconversion by fungi. Biotechnol Adv 2009, 27(2):185-194

19. $Y u$ Z, Zhang H: Pretreatments of cellulose pyrolysate for ethanol production by Saccharomyces cerevisiae, Pichia sp. YZ-1 and Zymomonas mobilis. Biomass Bioenerg 2003, 24:257-262.

20. Zhuang $X L$, Zhang HX, Tang JJ: Levoglucosan kinase involved in citric acid fermentation by Aspergillus niger CBX-209 using levoglucosan as sole carbon and energy source. Biomass Bioenerg 2001, 21:53-60.

21. Zhuang XL, Zhang HX, Yang JZ, Qi HY: Preparation of levoglucosan by pyrolysis of cellulose and its citric acid fermentation. Bioresource Technolog 2001, 79:63-66.

22. Kim TH, Lee $Y Y$ : Fractionation of corn stover by hot-water and aqueous ammonia treatment. Bioresource Technolog 2006, 97:224-232.

23. Ioannidou O, Zabaniotou A: Agricultural residues as precursors for activated carbon production-A review. Renew Sust Energ Rev 2007, 11:1966-2005

24. Yang Z, Kang H, He X, Zhuang G, Zhang H, Bai Z: Microbial Degradation and Utilization of Lignocellulosic Biomass Pyrolysis Oil. In Proceedings of the 2nd International Conference on Mechanic Automation and Control Engineering: July 15-17 1996; Hohhot. IEEE; 2011: 7457-7459.

25. Selvaggini C, Salmona M, Gioia LD: Manganese Peroxidase from Phanerochaete chrysosporium. Eur J Biochem 1995, 228:955-961.

26. Harazono K, Watanabe $Y$, Nakamura K: Decolorization of azo dye by the white-rot basidiomycete Phanerochaete sordida and by its manganese peroxidase. J Biosci Bioeng 2003, 95:455-459.

27. Kitamura Y, Yasui T: Purification and some properties of levoglucosan (1,6-anhydro- $\beta$-D-glucopyronose) kinase from the yeast sporolomyces salmonicolor. Agr Biol Chem 1991, 55:523-529.

28. Yasui T, Kitamura Y, Nakahara K, Abe Y: Metabolism of levoglucosan (1,6-anhydro- $\beta$-D-glucopyranose) in bacteria. Agr Biol Chem 1991, 55:1927-1929.

29. Yang Z, Liu X, Yang Z, Zhuang G, Bai Z, Zhang H, Guo Y: Preparation and formation mechanism of levoglucosan from starch using a tubular furnace pyrolysis reactor. J Anal Appl Pyrol 2013, 102:83-88.

30. Yang Z, Zhang B, Chen X, Bai Z, Zhang H: Studies on pyrolysis of wheat straw residues from ethanol production by solid-state fermentation. J Anal Appl Pyrol 2008, 81:243-246.

\section{Submit your next manuscript to BioMed Central and take full advantage of:}

- Convenient online submission

- Thorough peer review

- No space constraints or color figure charges

- Immediate publication on acceptance

- Inclusion in PubMed, CAS, Scopus and Google Scholar

- Research which is freely available for redistribution 